\title{
Metabolic engineering to enhance biosynthesis of both docosahexaenoic acid and odd-chain fatty acids in Schizochytrium sp. S31
}

Fangzhong Wang ${ }^{1}$, Yali $\mathrm{Bi}^{2,3,4}$, Jinjin Diao ${ }^{2,3,4}$, Mingming Lv $\mathrm{Lv}^{2,3,4}$, Jinyu Cui ${ }^{2,3,4}$, Lei Chen ${ }^{2,3,4}$ and Weiwen Zhang ${ }^{1,2,3,4^{*}}$

\begin{abstract}
Background: Docosahexaenoic acid (DHA, C22:6) and odd-chain fatty acids (OCFAs, C15:0 and C17:0) have attracted great interest, since they have been widely used in food and therapeutic industries, as well as chemical industry, such as biodiesel production and improvement. The oil-producing heterotrophic microalgae Schizochytrium sp. 31 is one of main DHA-producing strains. Recently, it was found that Schizochytrium can also synthesize OCFAs; however, contents and titers of DHA and OCFAs in Schizochytrium are still low, which limit its practical application.

Results: In this study, we found that acetyl-CoA carboxylase suffered from a feedback inhibition by C16-CoA in Schizochytrium, and relief of the inhibition resulted in improved both lipid content and the ratio of OCFAs in total fatty acids. Based on this finding, a novel strategy for elevating both DHA and OCFAs contents was established. First, the total lipid accumulation was increased by overexpressing a malic enzyme from Crypthecodinium cohnii to elevate NADPH supply. Second, the inhibition effect on acetyl-CoA carboxylase was relieved by overexpressing a codonoptimized $E L O 3$ gene from Mortierella alpina, which encodes an elongase enzyme responsible for converting C16 into C18 fatty acids. After the above two-step engineering, contents of DHA and OCFAs were increased by 1.39- and 3.30fold, reaching a level of 26.70 and $25.08 \%$ of dry cell weight, respectively, which are the highest contents reported so far for Schizochytrium. The titers of DHA and OCFAs were elevated by 1.08- and 2.57-fold, reaching a level of 3.54 and $3.32 \mathrm{~g} / \mathrm{L}$, respectively. Notably, the OCFAs titer achieved was 2.66 -fold higher than the highest reported in Escherichia coli $(1.25 \mathrm{~g} / \mathrm{L})$, implying potential value for industry application. To reveal the potential metabolic mechanism for the enhanced biosynthesis of both DHA and OCFAs, LC-MS metabolomic analysis was employed and the results showed that the pentose phosphate pathway and the glycolysis pathway were strengthened and intracellular propionyl-CoA concentration were also significantly increased in the engineered Schizochytrium, suggesting an increased supply of $\mathrm{NADPH}$, acetyl-CoA, and propionyl-CoA for DHA and OCFAs accumulation.
\end{abstract}

Conclusions: The discovery provides a new source of OCFAs production, and proposes a new strategy to improve contents and titers of both DHA and OCFAs in Schizochytrium. These will be valuable for improving commercial potential of Schizochytrium and guiding the engineering strategy in other fatty acids producing heterotrophic microalga.

Keywords: Docosahexaenoic acid, Odd-chain fatty acids, Malic enzyme, Acetyl-CoA carboxylase, Schizochytrium sp. S31

\footnotetext{
*Correspondence: wwzhang8@tju.edu.cn

${ }^{2}$ Laboratory of Synthetic Microbiology, School of Chemical Engineering \&

Technology, Tianjin University, Tianjin 300072, People's Republic of China

Full list of author information is available at the end of the article
} 


\section{Background}

Docosahexaenoic acid (DHA, C22:6) and odd-chain fatty acids (OCFAs, C15:0, and C17:0) have attracted significant attentions because of various practical applications. DHA is an essential fatty acid that cannot be synthesized by human. It has been reported that DHA plays an important role in the development of nervous and visual systems in infants and young children. And it also has the positive effects on decreasing the risk of cardiovascular disease. Like DHA, OCFAs are also beneficial to human health. It is reported that OCFAs have clear association with lower multiple sclerosis, coronary heart disease, and type II diabetes risk [1-5]. Meanwhile, OCFAs have various important industrial applications, such as the precursors of plasticizers, herbicides, pharmaceuticals, and fragrance intermediates [6-9]. Furthermore, adding OCFAs or their derivates into biodiesels can be helpful for further improving quality of biodiesels [9-12]. OCFAs are important in making ruminant products as they have lower melting points, and higher concentration of OCFAs can make fat softer in lambs [13].

The industrial production of DHA has been carried out by heterotrophic microalgae fermentation, such as Schizochytrium and Crypthecodinium [14, 15]. Due to the difficulty related to genetic manipulation in the microalga, most of previous work has focused on optimizing fermentation condition and strain selection. For example, it was reported that $28.93 \mathrm{~g} / \mathrm{L}$ of DHA and $151.40 \mathrm{~g} / \mathrm{L}$ of biomass were achieved by optimizing oxygen transfer in Schizochytrium sp. S31 [16].

In recent years, various strategies have been adopted to enhance DHA production in microalga. For example, the DHA productivity of Crypthecodinium cohnii was doubled using a two-step chemical modulators based on adaptive laboratory evolution strategy [17], and Agrobacterium-mediated transformation, electroporation, and particle bombardment have been established in Schizochytrium sp. TIO1101, Schizochytrium sp. PKU\#Mn4, and Schizochytrium sp. 31, respectively [18-20]. Although the efficiency is still low, metabolic engineering of Schizochytrium sp. to improve DHA accumulation has been gradually carried out [20-22]. For example, overexpression of anti-oxidative gene superoxide dismutase in Schizochytrium sp. PKU\#Mn4 increased polyunsaturated fatty acids production by 1.37 -fold [20].

Despite relatively few studies on OCFAs production were conducted so far, several strategies have been evaluated and the engineering of traditional fatty acid biosynthesis pathway is widely considered as an efficient strategy. For example, $1205 \mathrm{mg} / \mathrm{L}$ OCFAs were attained in Escherichia coli by increasing intracellular propionylCoA concentration and replacing enzymes involved in the initialization step of fatty acid elongation by enzymes with higher propionyl-CoA affinity [9]. Blocking competitive and degradation pathway and enhancing the downstream pathway are also used for OCFAs or derivatives production. In Yarrowia lipolytica, the ratio of OCFAs to total lipid was increased 1.65 -fold by blocking the catabolic pathway of propionyl-CoA. Further genetic engineering by blocking $\beta$-oxidation, degradation of triacylglycerols, and pushing triacylglycerols biosynthesis, OCFAs content in dry cell weight was increased by 5.34-fold [12]. OCFAs or their derivatives can be manufactured by directly oxidation of even chain fatty acids. Cao et al. reported that the odd-chain fatty aldehydes can be formed by incorporating $\alpha$-dioxygenase from Oryza sativa into $E$. coli to directly oxidize even chain $C_{n}$ fatty acids into odd-chain $C_{n-1}$ fatty acids [23]. In addition to above-mentioned strategies, other novel methods have been developed for odd-chain molecules synthesis. For example, the E. coli can produce $\mathrm{C} 7, \mathrm{C} 9$, and $\mathrm{C} 11$ fatty alcohols by reversal of the beta-oxidation cycles with supplement of propionate in the medium [24]. By adaptation of the butanol biosynthetic pathway and development of a complementary modular toolkit, E. coli can be engineered to synthesize various odd-chain products in a controlled manner [25].

The oleaginous heterotrophic microalgae Schizochytrium sp. S31 has received much attention as it can achieve high biomass accumulation with high percent of oil and DHA content. Until now, the highest yield and productivity of DHA were achieved using Schizochytrium sp. S31 [16]. Actually, it has been successfully applied for industrial production of DHA in several countries [14, $16,26]$. Recently, it was also found that the proportion of OCFAs in total fatty acids of Schizochytrium sp. S31 was much higher than those of other Schizochytrium strains [26-29]. Therefore, we propose that Schizochytrium sp. S31 could be an ideal candidate for producing both DHA and OCFAs. Such effort will not only provide a novel source for the production of OCFAs, but also improve commercial and industrial potential of Schizochytrium sp. S31.

In this study, inhibition effect on acetyl-CoA carboxylase activity was observed in Schizochytrium, and converting $\mathrm{C} 16$ into $\mathrm{C} 18$ fatty acids could relieve the inhibition effect, resulting in elevated content of total lipid and the ratio of OCFAs in total fatty acids. Based on the finding, a novel strategy for elevation of both DHA and OCFAs content was successfully applied in Schizochytrium. First, the total lipid accumulation was increased by reinforcing NADPH supply through overexpression of a malic enzyme. Second, coding gene of an elongase enzyme responsible for converting C16 into C18 was overexpressed to relieve the inhibition effect on acetyl-CoA carboxylase activity. After the modification, 
contents and titers of both DHA and OCFAs were significantly enhanced. The study also provides useful information to engineer microalgae for other high-valued fatty acid production.

\section{Results}

\section{Lipid and OCFAs contents increased by overexpression} of ELO3 in Schizochytrium

Feedback inhibition of enzymes controlling the early steps of biosynthetic pathways was well observed in many microorganisms when the final products were accumulated at large quantitation [30, 31]. Early reports showed that C16-CoA (a kind form of C16:0) was able to feedback inhibit activity of acetyl-CoA carboxylase (ACC), an enzyme controlling the first committed step of fatty acid biosynthesis in many organisms (Fig. 1) [32]. Meanwhile, a previous study found that the content of C16:0 fatty acids in dry cell weight was as high as approximately $12.79 \%$ in Schizochytrium [29], which prompted us to explore whether the similar feedback inhibition mechanism is existing. The cell-free extract of Schizochytrium sp. 31 was prepared. The 50 or $100 \mu \mathrm{M}$ of C16-CoA was added into the cell-free extraction and then acetyl-CoA carboxylase activity was determined. The results showed that acetyl-CoA carboxylase activity was decreased $38.24 \%$ or $44.98 \%$ in the presence of 50 or $100 \mu \mathrm{M}$ of
C16-CoA, respectively (Additional file 1: Fig. S1). Therefore, we concluded that acetyl-CoA carboxylase suffered from inhibition by $\mathrm{C} 16-\mathrm{CoA}$.

A codon-optimized ELO3 gene derived from Mortierella alpina has been well characterized with a high activity of converting C16 into C18 [33, 34]. Recently, it was also used for improving eicosapentaenoic acid (EPA, an omega-3 fatty acid) production in Yarrowia lipolytica [35]. ELO3 is carbon chain length-specific enzyme, as the previous study showed that it can efficiently convert $\mathrm{C} 16: 0$ into $\mathrm{C} 18: 0$, but cannot convert $\mathrm{C} 17: 0$ into C19:0 [33]. Therefore, ELO3 gene was chosen and transformed into Schizochytrium sp. S31 via electroporation. The schematic map of the ELO3 expression cassette was shown in Additional file 1: Fig. S2A. After two rounds of neomycin selections, transformants were confirmed by PCR, as the PCR analysis of a positive transformant named S-E strain showed a $1.51 \mathrm{~kb}$ expected PCR band using primer 1 and 2 , while no band was presented in the wild type (Additional file 1: Fig. S2B). Correspondingly, the transcript of the ELO3 gene was successfully detected in the S-E strain, but not in the wild type (Additional file 1: Fig. S2C), demonstrating that ELO3 gene has been successfully transformed into Schizochytrium.

Analysis showed that the lipid content was increased by $12.87 \%$ at $72 \mathrm{~h}$ (Fig. $2 \mathrm{~b}$ ), although the growth rate

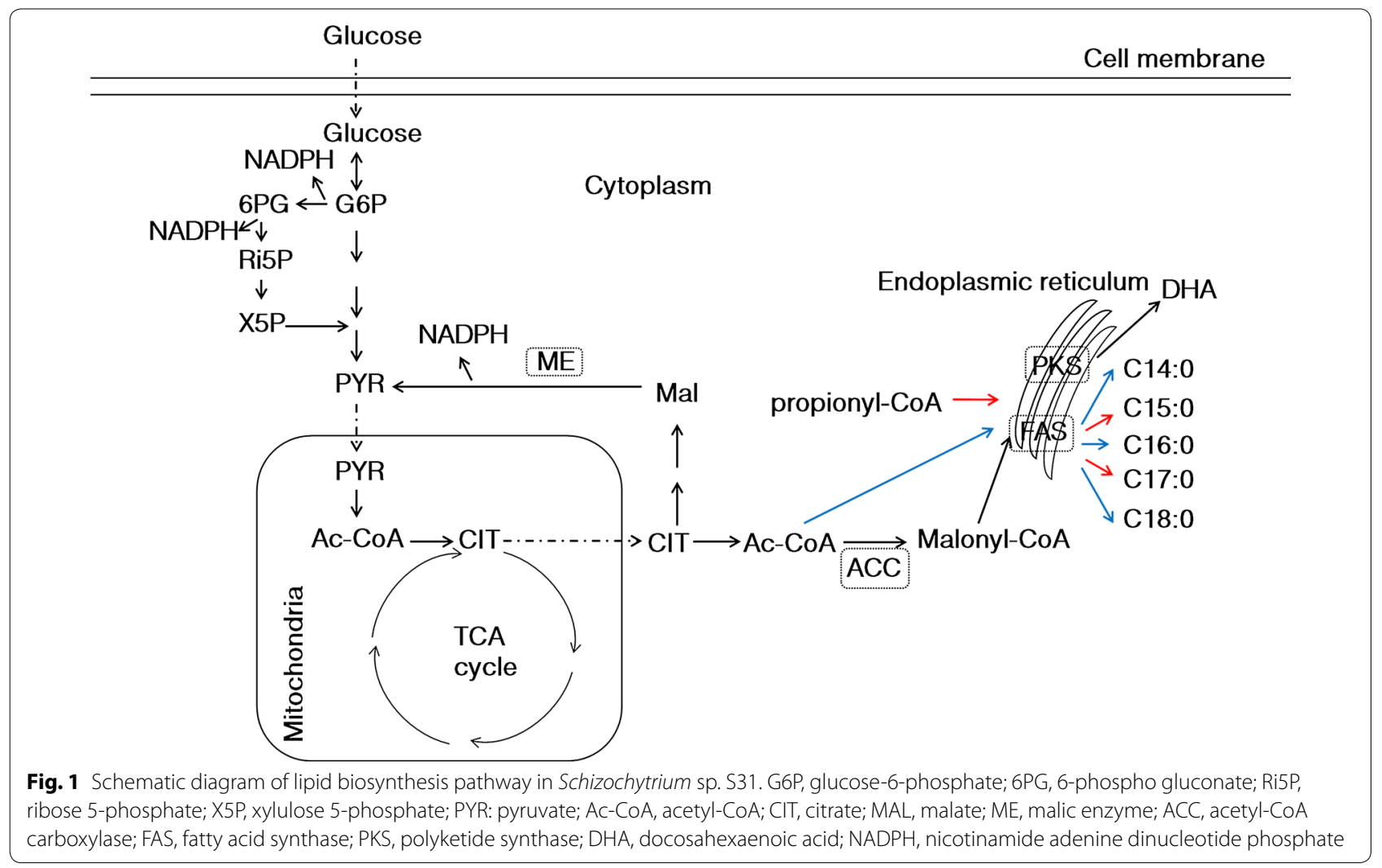


a
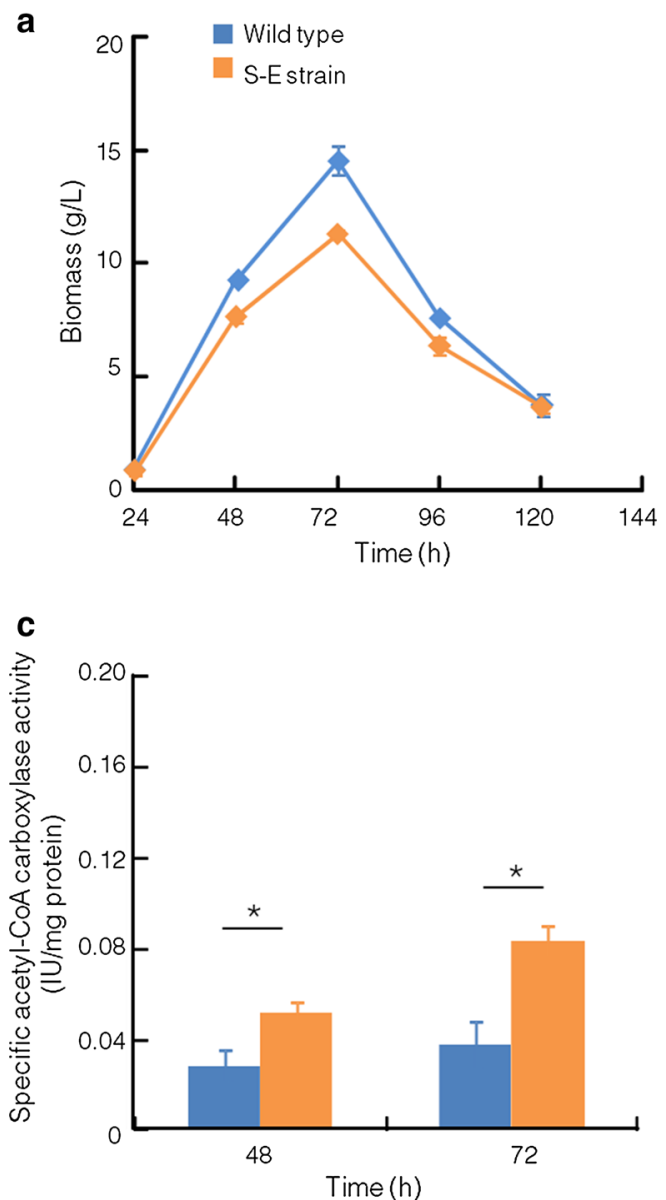

b

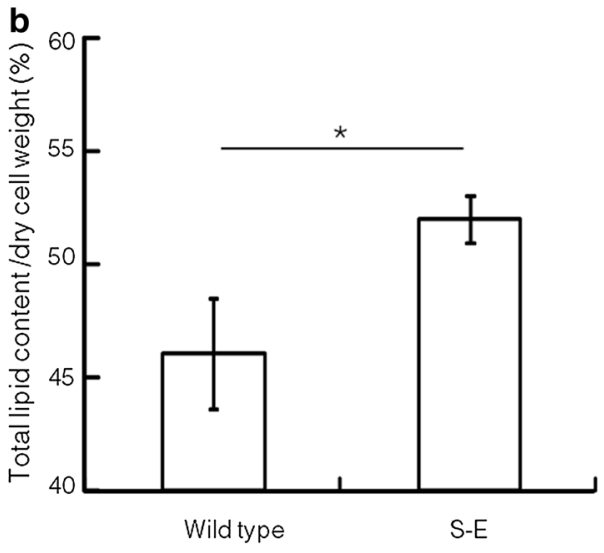

d

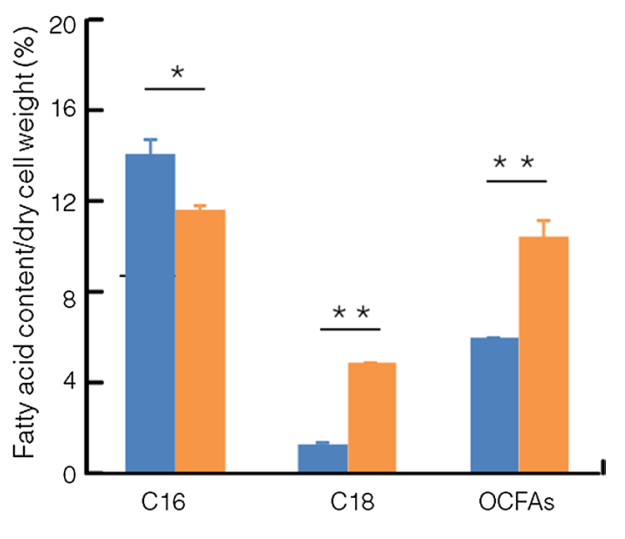

Fig. 2 Comparison of growth curves, lipid contents and acetyl-CoA carboxylase activity between wild type and S-E. a Growth curves; $\mathbf{b}$ lipid content; $\mathbf{c}$ acetyl-CoA carboxylase activity; $\mathbf{d}$ fatty acid contents. blue: wild type; orange: S-E strain. ${ }^{*} p<0.05 ;{ }^{* *} p<0.01 . \mathrm{C} 14, \mathrm{C} 14: 0 ; \mathrm{C16}, \mathrm{C16}: 0 ; \mathrm{C} 18$, C18:0 and C18:1; OCFAs, odd-chain fatty acids (C15:0 + C17:0)

and highest biomass accumulation of S-E strain were slightly lower than those of the wild type (Fig. 2a). And the activity of acetyl-CoA carboxylase was significantly up-regulated at 48 and $72 \mathrm{~h}$ in S-E strain $(p<0.05$, $n=3$ ) (Fig. 2c). Therefore, it seemed more carbon source was directed into lipid biosynthesis by up-regulating acetyl-CoA carboxylase activity (Fig. 1). Further analysis showed that similar to the change of lipid content, the contents of $\mathrm{C} 18$ fatty acids were also significantly increased, which was up-regulated by 3.82 -fold. However, the C16:0 content was decreased by $17.30 \%$ at $72 \mathrm{~h}$ (Fig. 2d), which may be due to the increased conversion and carbon flow of $\mathrm{C} 16$ into $\mathrm{C} 18$ by ELO3 in S-E strain. These results suggested that feedback inhibition on acetyl-CoA carboxylase could be partially released by expressing ELO3 gene in Schizochytrium sp. S31. Interestingly, the ratio of OCFAs in total fatty acids was increased by $27.42 \%$ in S-E strain (Additional file 2: Table S1).

\section{Lipid content increased by overexpressing a malic enzyme} gene from C. cohnii in Schizochytrium

It was previously reported that the total lipid content of Schizochytrium sp. HX-308 was increased by $15 \%$ after adding $4 \mathrm{~g} / \mathrm{L}$ malic acid to elevate malic enzyme activity at rapid lipid accumulation stage [36]. In addition, the content of total fatty acids was decreased by $50 \%$ after malic enzyme activity was inhibited, demonstrating the important role of the malic enzyme during lipid biosynthesis in C. cohnii [37]. Therefore, efforts were made to increase total lipid content by overexpressing a malic enzyme gene from C. cohnii in Schizochytrium. The expression cassette containing malic enzyme and neomycin resistance genes was transformed into Schizochytrium via electroporation to obtain S-M strain (Additional file 1: Fig. S3A). A $1.84 \mathrm{~kb}$ DNA band was detected in the PCR with the S-M strain, but not with the wild type (Additional file 1: Fig. S3B). RT-PCR showed that a malic enzyme fragment was successfully amplified from the cDNA of S-M strain; in 
contrast, no product was detected in the wild type (Additional file 1: Fig. S3C). To further confirm that the malic gene was expressed at the protein level, cells of S-M and wild-type strains were collected at 48 and $72 \mathrm{~h}$ during fermentation in the rich medium. The cell-free extracts were prepared to determinate the malic enzyme activity and NADPH content. The results showed that the malic enzyme activity of the S-M strain was 1.83- and 2.45-fold higher than that of the wild type, and NADPH content was increased 1.67- and 2.52-fold in the S-M strain at 48 and $72 \mathrm{~h}$, respectively (Additional file 1: Fig. S4). These results indicated that the malic enzyme from $C$. cohnii has been successfully integrated into Schizochytrium genome and functionally expressed.

As shown in Fig. 3a, the growth curves of two strains varied slightly, and the biomass accumulation reached the peak at $72 \mathrm{~h}$ of the fermentation and then quickly decreased. Cells were harvested at 72 and $96 \mathrm{~h}$ and then subjected to total lipid extraction analysis. As shown in Fig. 3b, the total lipid yield of the S-M strain was increased approximately $39.26 \%$ and $40.15 \%$, reaching up to $67.16 \%$ and $63.71 \%$ in its cell dry weight at 72 and $96 \mathrm{~h}$, respectively. Nile red staining analysis was also used to determine the neutral lipid accumulation. The fluorescence intensity of S-M strain was also significantly increased, comparing to the wild type $(p<0.05, n=3)$
(Fig. 3c). Four genes associated with fatty acid biosynthesis were analyzed by qRT-PCR at 48 and $72 \mathrm{~h}$. FAS gene, which is involved in saturate fatty acid biosynthesis, was up-regulated 2.92- and 7.55-fold in S-M strain (Fig. 3d), and three genes directly related to DHA biosynthesis, $\operatorname{orf} \mathrm{A}, \operatorname{orf} \mathrm{B}$, and $\operatorname{orfC}$, were also significantly up-regulated $(p<0.05, n=3)$ (Fig. 3e). These results suggested that overexpression of the malic gene from $C$. cohnii significantly promoted lipid synthesis; meanwhile, no compromise of cell growth was observed in the engineered Schizochytrium.

Compared to the wild type, the contents of DHA, OCFAs, C16:0, and C18 were increased $16.94 \%, 53.25 \%$, $38.89 \%$, and $75.37 \%$, respectively in the S-M strain (Fig. 4), while the acetyl-CoA carboxylase activity was significantly decreased in the S-M strain at 48 and $72 \mathrm{~h}$ $(p<0.05, n=3)$ (Fig. 3f). These results further confirmed that acetyl-CoA carboxylase suffered feedback inhibition in the S-M strain, and it is a potential metabolic engineering target for further enhancing DHA and OCFAs contents in Schizochytrium sp. S31.

\section{Elevated DHA and OCFAs contents by relieving inhibition effect on acetyl-CoA carboxylase in the S-M strain}

As mentioned above, overexpression of ELO3 gene relieved inhibition effect on acetyl-CoA carboxylase in

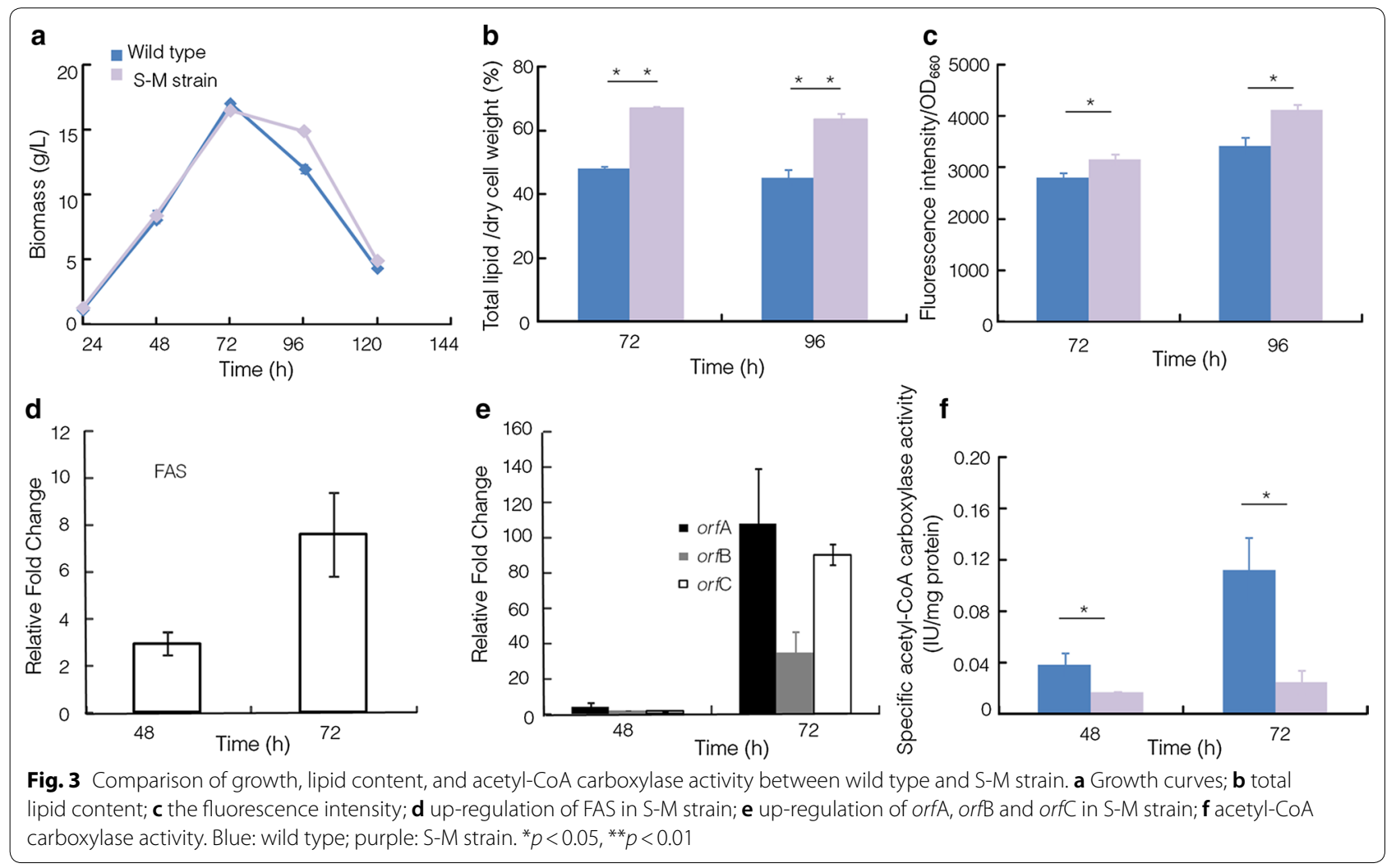




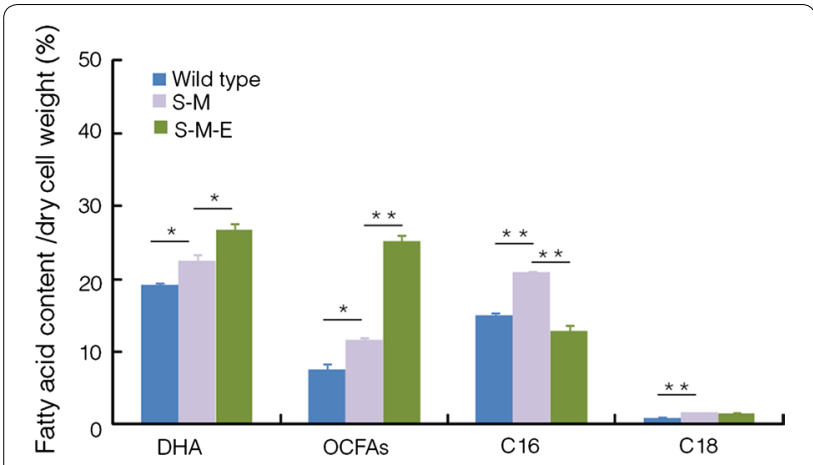

Fig. 4 Comparison of the fatty acid contents among strains. Blue: wild type; purple: S-M strain; green: S-M-E strain. ${ }^{*} p<0.05 .{ }^{* *} p<0.01$. DHA, docosahexaenoic acid; C16, C16:0; C18, C18:0, and C18:1; OCFAs, odd-chain fatty acids (C15:0 + C17:0)

Schizochytrium sp. S31. Therefore, the expression cassette containing ELO3 and zeoR was transformed into the S-M strain. A positive transformant named S-M-E strain was confirmed by both PCR and RT-PCR (Additional file 1: Fig. S5). Similar to the S-M strain, malic enzyme activity was significantly up-regulated in the S-M-E strain, in comparison with that in the wild type strain (Fig. 5a), suggesting that ELO3 gene was successfully integrated into the $\mathrm{S}-\mathrm{M}$ genome, and no interference on the function of the previously integrated malic gene was observed.

The S-M and S-M-E strains were in parallel inoculated into the rich fermentation medium. It was observed that the growth rate of S-M-E was slower than that of S-M. Both of them entered the stationary phase at the $72 \mathrm{~h}$, but the highest biomass accumulation of the S-M-E was lower by $19.57 \%$ (Fig. 5 b). The total lipid contents were also analyzed, and results showed a $6.73 \%$ or $12.97 \%$ increase of total lipid contents in the S-M-E strain at the 72 or $96 \mathrm{~h}$, respectively, compared with the S-M strain (Fig. 5d). The fluorescence intensity of S-M-E strain was also significantly increased in comparison with that of S-M strain at the 72 and $96 \mathrm{~h}(p<0.05, n=3)$ (Fig. 5e). In addition, compared with the S-M strain, C16:0 content was decreased by $38.24 \%$, and the contents of DHA and OCFAs were increased 1.19- and 2.16-fold in the S-M-E strain, respectively (Fig. 4). Furthermore, the acetyl-CoA carboxylase activity of S-M-E strain was significantly up-regulated at the 48 and $72 \mathrm{~h}(p<0.05, n=3)$ (Fig. 5c). Therefore, the feedback inhibition effect on acetyl-CoA carboxylase seemed relieved in the S-M-E strain.

The schematic diagram of the changes of DHA, OCFAs, and C16:0 contents after two-step metabolic engineering is shown in Fig. 6. The GS/MS spectra of fatty acids profiles of all these strains are provided in

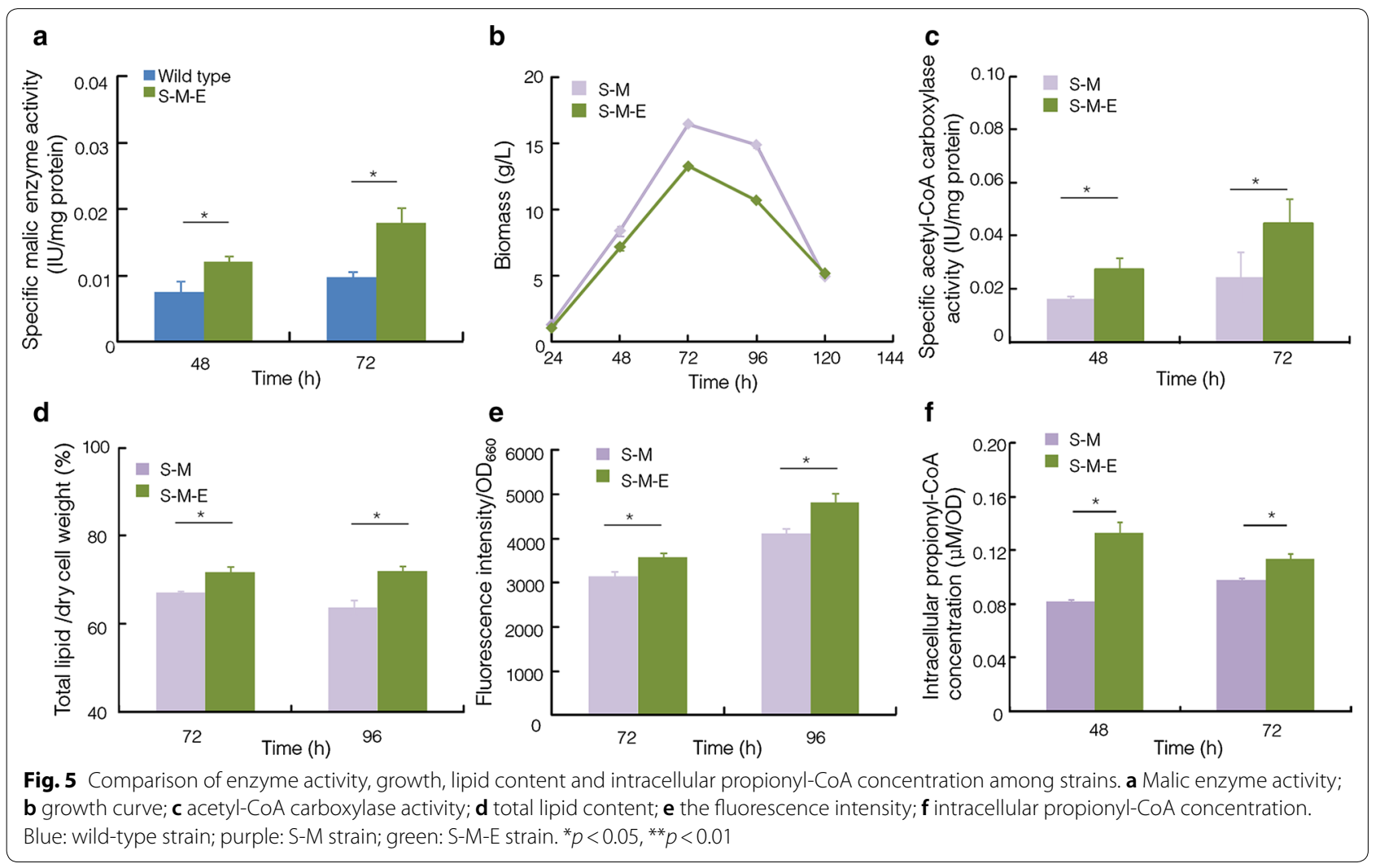



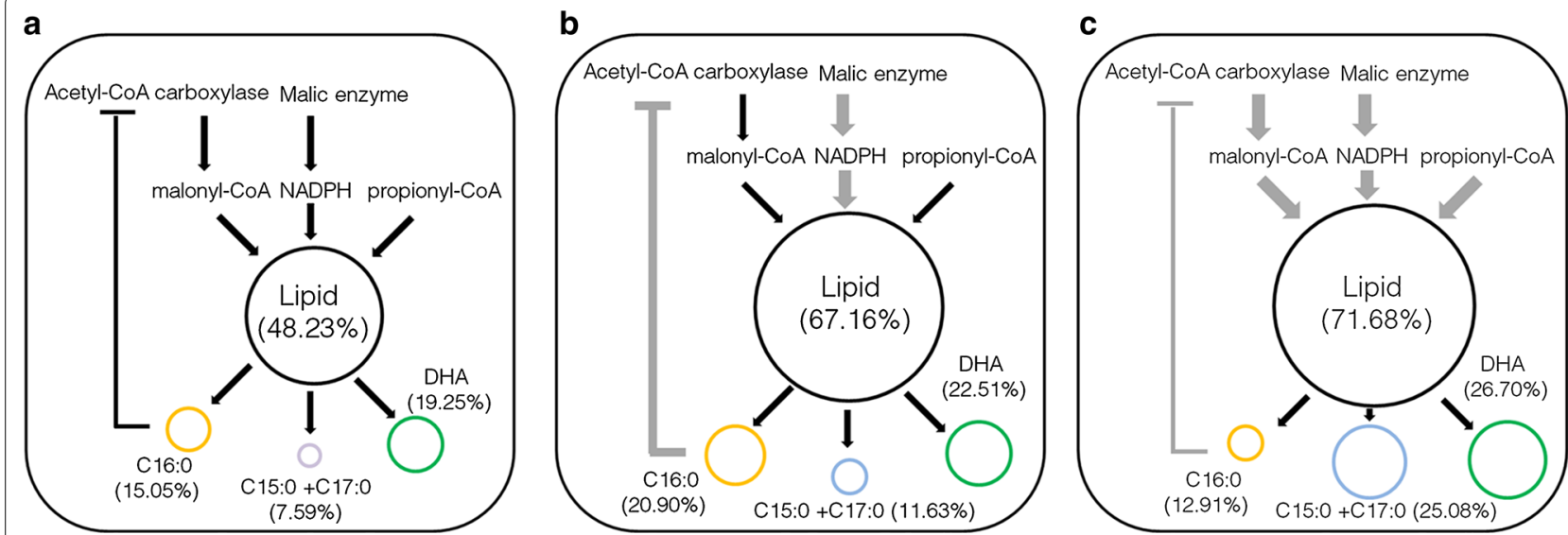

Fig. 6 Schematic diagram of metabolic engineering strategy used in this study. a Wild-type strain; b S-M strain; c S-M-E strain. Black circle represents total lipid, yellow circle represents C16:0, blue circle represents OCFAs (C15:0+C17:0), and green circle represents DHA. Black lines represent original pathway, and gray lines represent enhanced (bold) or decreased (slim) original pathways after engineering

Fig. 7 and Additional file 1: Fig. S6. The contents of lipids, DHA, and OCFAs were increased 1.49-, 1.39-, and 3.30fold, reaching a level of $71.68,26.70$, and $25.08 \%$ of dry cell weight, in the final engineered Schizochytrium sp.
S31. And the titers and yields of biomass, lipid, DHA, and OCFAs are summarized in Table 1. Notably, the OCFAs titer was $3.32 \mathrm{~g} / \mathrm{L}$, which was much higher than the highest report so far in E. coli $(1.25 \mathrm{~g} / \mathrm{L})$ [9].

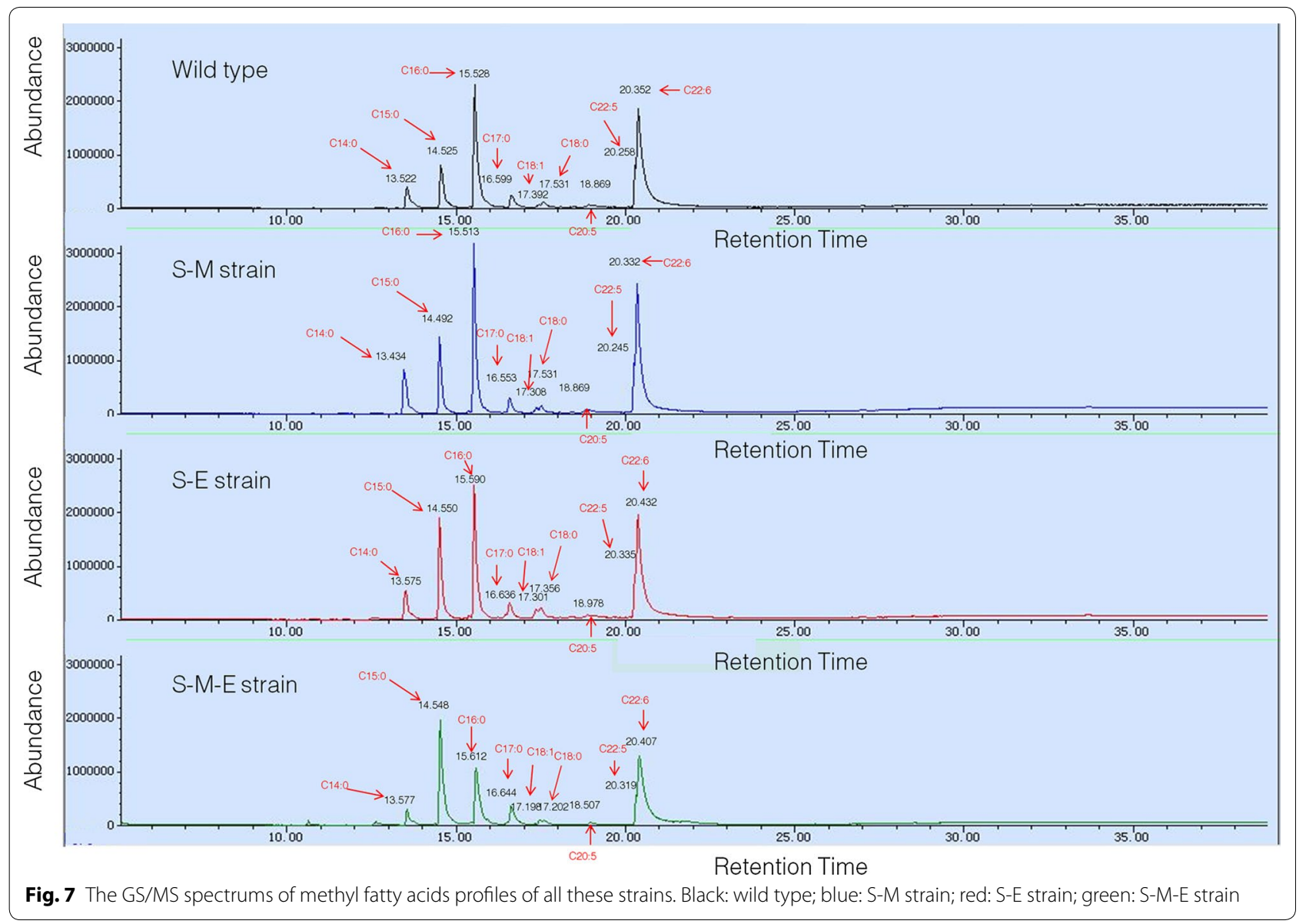


Table 1 Comparison of biomass, lipid, DHA, and OCFAs production in parent, S-M and S-M-E strains

\begin{tabular}{|c|c|c|c|c|c|c|c|c|}
\hline & \multicolumn{2}{|l|}{ Biomass } & \multicolumn{2}{|l|}{ Lipid } & \multicolumn{2}{|l|}{ DHA } & \multicolumn{2}{|l|}{ OCFAs } \\
\hline & Titer (g/L) & Yield (g/g) & Titer (g/L) & Yield $(g / g)$ & Titer (g/L) & Yield $(g / g)$ & Titer (g/L) & Yield (g/g) \\
\hline Parent & $17.04 \pm 0.19$ & $0.43 \pm 0.00$ & $8.22 \pm 0.13$ & $0.21 \pm 0.00$ & $3.28 \pm 0.09$ & $0.08 \pm 0.00$ & $1.29 \pm 0.11$ & $0.03 \pm 0.00$ \\
\hline S-M & $16.48 \pm 0.11$ & $0.41 \pm 0.00$ & $11.07 \pm 0.02$ & $0.28 \pm 0.00$ & $3.71 \pm 0.14$ & $0.09 \pm 0.00$ & $1.92 \pm 0.05$ & $0.05 \pm 0.00$ \\
\hline S-M-E & $13.25 \pm 0.02$ & $0.33 \pm 0.00$ & $9.50 \pm 0.19$ & $0.24 \pm 0.00$ & $3.54 \pm 0.11$ & $0.09 \pm 0.00$ & $3.32 \pm 0.14$ & $0.08 \pm 0.00$ \\
\hline
\end{tabular}

\section{Comparative metabolomics analysis of S-M and S-M-E strains}

The LC-MS metabolomics have been established for quantifying metabolites related to central carbon metabolic pathway in microalgae previously in our laboratory $[17,38]$. Therefore, it was applied to investigate possible mechanism related to enhanced accumulation of DHA and OCFAs in the S-M-E strain. Cells were harvested at 48 and $72 \mathrm{~h}$, which are corresponding to exponential and stationary phases of the fermentation, and subjected to quantitative analysis of the targeted intracellular metabolites (Additional file 2: Table S2). The reliability of LC-MS metabolomics analysis was demonstrated by the principal component analysis. It was shown that three biological replicates of each sample were clearly clustered together, suggesting a good reproducibility (Additional file 1: Fig. S7). Meanwhile, the samples of S-M and S-M-E strains were visibly separated, suggesting that the metabolic change between the two strains can be detected by the analysis.

Heatmaps of targeted metabolite analysis in all samples were constructed by MultiExperiment Viewer software (Fig. 8). It was shown that, at $48 \mathrm{~h}$, intercellular abundance of NADPH, NAD, ATP, ADP, F6P, R5P, Citric, GAP, PEP, GLU, AKG, OXA, and SUM was up-regulated, while intercellular abundance of NADP, MAl, PHE, LYS, LEU, and VAL was down-regulated in the S-M-E strain; at $72 \mathrm{~h}$, intercellular abundance of NADPH, NAD, ATP, FBP, F6P, R5P, Citric, 3-PG, GAP, PEP, GLU, SUM, FUM, and Ac-CoA was up-regulated, and intercellular abundance of NADP, MAl, PHE, LYS, ASP, LEU, VAL, and ALA was down-regulated in S-M-E strain. Metabolic analysis of the metabolomic data showed that: (i) pentose phosphate pathway was up-regulated, as two key metabolites, GAP and R5P, were all up-regulated at both 48 and $72 \mathrm{~h}$ in the S-M-E strain. Pentose phosphate pathway is known to produce NADPH. In oleaginous yeast, up-regulation of pentose phosphate pathway resulted in significantly increase of lipid content, while, in Aurantiochytrium sp. SD116, strengthening pentose phosphate pathway increased the proportion of DHA in total lipids [39-41]; (ii) glycolysis pathway seemed strengthened as the up-regulation of FBP, F6P, 3-PG, and PEP was observed. The increased glycolysis pathway could lead to

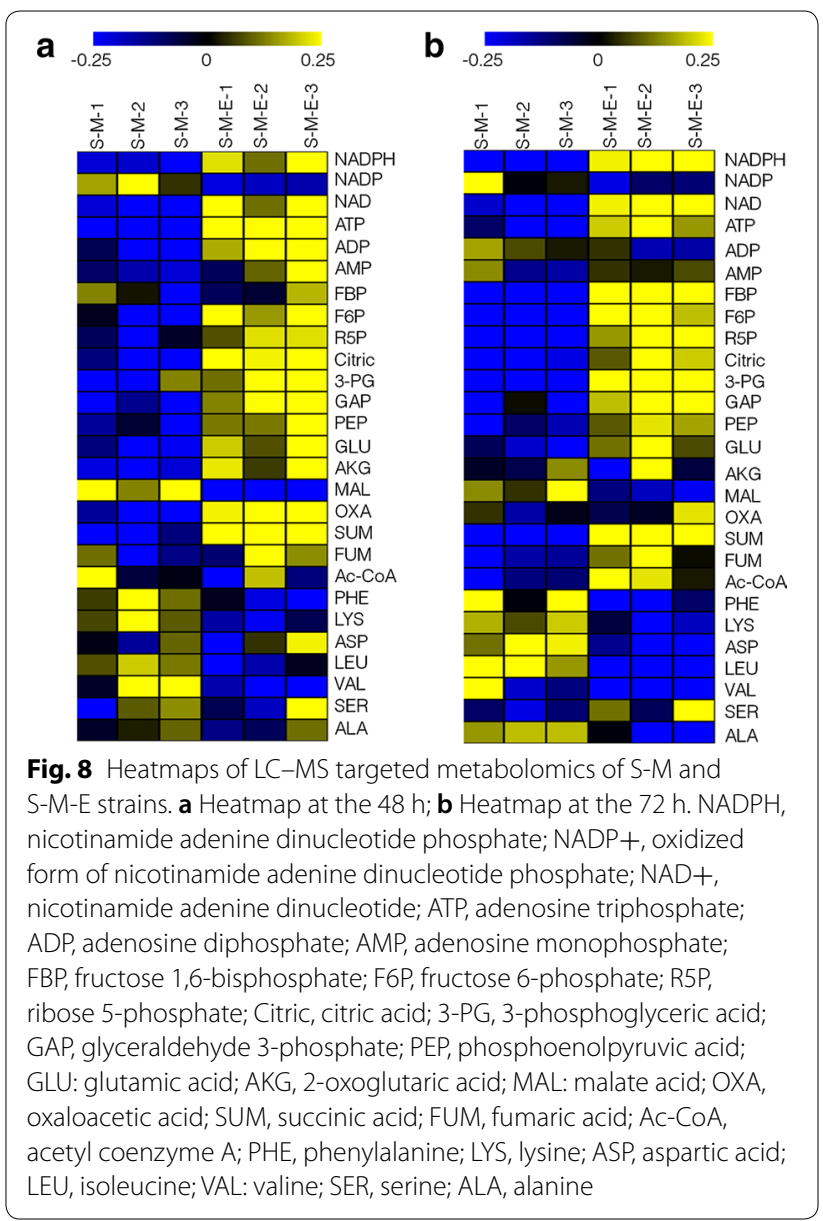

more Ac-CoA and ATP produced, which will further promote fatty acid accumulation [42, 43]; (iii) the lipid biosynthetic pathway seemed enhanced as the precursors of lipid biosynthesis, Ac-CoA and NADPH, was increased. We determined and compared the intracellular propionyl-CoA concentration between S-M and S-M-E strains, and the results showed that the propionyl-CoA concentration of S-M-E strain was significantly higher than that of S-M strains (Fig. 5f). In summary, we speculated that a possible mechanism responsible for increased DHA and OCFAs' contents in S-M-E strain might be involved in up-regulation of pentose phosphate pathway, glycolysis 
pathway, and intracellular propionyl-CoA concentration to increase a supply of NADPH, acetyl-CoA, and propionyl-CoA for lipid biosynthesis.

\section{Discussion}

Rational design of microbial factories has been widely used for production of high-value biochemicals. Recent studies on metabolic engineering for DHA production have mainly focused on Schizochytrium and Crypthecodinium, while E. coli and Y. lipolytica are usually used as hosts for OCFAs production. However, few reports focused on simultaneously producing high amounts of DHA and OCFAs in one microorganism. To maximize metabolic efficiency and potential value of Schizochytrium fermentation, we decided to produce both DHA and OCFAs simultaneously, as DHA and OCFAs can be separated and purified from the mixture by very established and low-cost method of urea complexation [44]. One of the main challenges in the industrial production of fatty acids from Schizochytrium is the high production cost $[45,46]$. Compared with early reports [19-21], the strategy which we developed can significantly improve the contents and titers of DHA and OCFAs in Schizochytrium, especially the contents of DHA and OCFAs. Therefore, the total fatty acid production cost could be significantly decreased (Additional file 2: Table S3).

Yarrowia lipolytica and E. coli have been used for OCFAs production, and the exogenous propionate, which can be converted into propionyl-CoA, is supplemented into glucose medium to enhance intracellular propionylCoA concentration $[9,12]$. Even so, the content of OCFAs in Y. lipolytica ( $2.30 \%, \mathrm{~g} / \mathrm{g}$ dry cell weight, wild type) was still much lower than that in Schizochytrium $(5.59 \%, \mathrm{~g} / \mathrm{g}$ dry cell weight, wild type), which only used glucose as carbon source [12, 29]. For E. coli, in addition to above issues, a key defect is phage contamination, which could result in cell death, during industrial application, in comparison with other eukaryotic microorganisms [47]. Schizochytrium exhibited strong robustness and has already widely used for industrial production of DHA. The precursors of lipogenesis are abundant, since the oil content can reach roughly $50-55 \%$ in dry cell weight [16]. In this study, we did not add propionate into medium, but the OCFAs titer $(3.32 \mathrm{~g} / \mathrm{L})$ in the final engineered strains was 2.66-fold higher than the highest report so far $(1.25 \mathrm{~g} / \mathrm{L})$, which was achieved in the presence of propionate in E. coli [9]. Above all, Schizochytrium could be a new candidate for industrial production of OCFAs.

The primary source for lipogenic NADPH was varied in different species. In Yarrowia lipolytica, it was reported that pentose phosphate pathway is responsible for generating NADPH for lipogenesis, while malic enzyme might not be involved in lipid accumulation [39-41]. In our study, we found that both malic enzyme and pentose phosphate pathway are important to increase NADPH availability for lipid synthesis in Schizochytrium sp. S31. Although the genome of Schizochytrium sp. S31 has not been sequenced, the fatty acid pathways have been well characterized previously $[48,49]$. The early studies showed that polyunsaturated fatty acids were synthesized by polyunsaturated fatty acid synthase (PUFA), while short or medium fatty acids (including OCFAs) were synthesized by fatty acid synthase (FAS). It has been proposed that NADPH produced by malic enzyme-involved transhydrogenase system was preferred for supporting biosynthesis of saturated fatty acid through the FAS pathway [37, 50-52], and NADPH produced by pentose phosphate pathway was closely involved in DHA production by PKS pathway $[37,50,52,53]$. In this study, it was found that overexpression of malic enzyme was able to increase the ratio of C16:0 and OCFAs in total lipid and strengthened pentose phosphate pathway increased the percentage of DHA in total lipid (Fig. 6), consistent with the early conclusion $[37,50,52,53]$. These results also suggested that regulation mechanisms of FAS and PKS pathways could be different, which may result in increase of DHA and OCFAs at different folds.

The lipogenesis begins by the action of acetyl-CoA carboxylase, and ends by an thioesterase for hydrolyzing C16- or C18-ACP into mature $\mathrm{C} 16$ or $\mathrm{C} 18$ fatty acids [51] (Fig. 1). To our knowledge, there is only one research on inhibition effect of acetyl-CoA carboxylase in microalga [32], but lacks evidence in vivo and methods for alleviating the inhibition effect. In our study, in vitro study showed that acetyl-CoA carboxylase suffered from inhibition by C16-CoA, and in vivo study showed that decreasing the content of C16 fatty acid was able to elevate acetyl-CoA carboxylase activity and increasing C16 fatty acid content decreased acetyl-CoA carboxylase activity. Therefore, we concluded that there exists a feedback inhibition effect on acetyl-CoA carboxylase by C16CoA or other forms of C16 in Schizochytrium sp. S31. We also proposed a novel strategy to release the inhibition of acetyl-CoA carboxylase by overexpressing $E L O 3$ genes to convert $\mathrm{C} 16$ into $\mathrm{C} 18$, not by overexpressing thioesterase to hydrolyze fatty acid-ACP into free fatty acid.

Literature also pointed that the similar feedback inhibition mechanism might also exist in other microalgae. For example, although no increase of lipid content has been reported by overexpressing acetyl-CoA carboxylase in $C$. reinhardtii [54], overexpression of acyl-ACP thioesterase was found to efficiently improve lipid content [55], suggesting that overexpression of acetyl-CoA carboxylase gene could result in increased $\mathrm{C} 16$ or its intermediates contents and, correspondingly, a feedback inhibition of 
acetyl-CoA carboxylase activity, while overexpression of acyl-ACP thioesterase facilitated the subsequent conversion of $\mathrm{C} 16$ or its intermediates into triacylglycerols, leading to relief of the inhibition and the elevated lipid biosynthesis.

We also found that the up-regulation of OCFAs content was accompanied by the slight decrease of biomass accumulation. It is a common phenomenon observed previously in E. coli and Y. lipolytica $[9,12]$, but the underlying mechanism is unclear. LC-MS metabolomics suggested that Krebs cycle seemed not under-regulated in the S-M-E strain, suggesting not the metabolic burden that has caused the growth repression. It is an interesting question that we will further explore in the future.

\section{Conclusions}

In this study, a two-step engineering strategy was established to increase the contents and titers of DHA and OCFAs in Schizochytrium. First, total lipid accumulation was increased by reinforcing NADPH supply. Second, the inhibition effect on acetyl-CoA carboxylase activity was relieved to further elevate lipid content and, meanwhile, improve the ratios of OCFAs in total fatty acids. After metabolic engineering, contents and titers of DHA and OCFAs achieved a level of 26.70 and $25.08 \%$ of dry cell weight, respectively, representing the highest contents in Schizochytrium so far. Furthermore, the final strain produced $3.32 \mathrm{~g}$ OCFAs/L medium, which was the highest titer reported so far. DHA and OCFAs are important health products and industrial intermediates. The efforts can improve commercial potential of Schizochytrium, and provide valuable reference for production of highvalue products in microalga.

\section{Methods}

\section{Strains and cultivation}

Schizochytrium sp. S31 (ATCC 20888) was obtained from the American Type Culture Collection (MD, USA) and cultivated in a basal liquid medium contained $5.0 \mathrm{~g} / \mathrm{L}$ glucose, $1.0 \mathrm{~g} / \mathrm{L}$ yeast extract (OXOID, Basingstoke, UK), $1.0 \mathrm{~g} / \mathrm{L}$ peptone, and $20.0 \mathrm{~g} / \mathrm{L}$ sea salt (Sigma-Aldrich, St. Louis, MO, USA). The seed cultures were cultivated in basal liquid medium at $25^{\circ} \mathrm{C}$ and shaken at $180 \mathrm{rpm}$ for $48 \mathrm{~h}$, and $5 \%(v / v)$ of seed cultures were transferred into rich fermentation medium containing $40 \mathrm{~g} / \mathrm{L}$ glucose, $5 \mathrm{~g} / \mathrm{L}$ peptone, $10 \mathrm{~g} / \mathrm{L}$ yeast extract, and $20 \mathrm{~g} / \mathrm{L}$ sea salt.

\section{Construction of gene expression cassette}

All the plasmids were constructed using Seamless Cloning kit (Biomed, Beijing, China). CaMV35s promoter, CaMV poly(A) terminator and Nos terminator were amplified from the P1301-egfp plasmid. The 18s upstream, downstream, and $\alpha$ tubulin promoter were amplified from the Schizochytrium genome. The malic enzyme gene (GFIV01087707.1) was amplified from the cDNA of C. cohnii ATCC 30556. Neomycin resistance gene, bleomycin resistance gene, codon-optimized Mortierella alpina ELO3 gene (Additional file 3: file S1), and CYC1 terminator were synthesized by Genewiz Company (Suzhou, China). The schematic maps of gene expression cassette are shown in Additional file 1: Figs. $\mathrm{S} 1, \mathrm{~S} 2$ and S3. The gene expression cassette was ligated into the Pug6 plasmid and stored in $-20^{\circ} \mathrm{C}$ until use.

\section{Transformation of Schizochytrium}

Transformation of Schizochytrium was conducted following the method described previously with modification [56]. Ten milliliters of mid-log phase cells were harvested and washed using solution containing 5.0\% PEG 8000 and $20 \mathrm{~g} / \mathrm{L}$ sea salt for once. The cells were re-suspended in $0.4 \mathrm{~mL}$ of the same solution and added into a $1.5 \mathrm{~mL}$ microcentrifuge tube containing $250 \mathrm{mg}$ of sterilized zirconia. The $1.5 \mathrm{~mL}$ microcentrifuge tubes were agitated at top speed on a Vortex Genie II mixer for $30 \mathrm{~s}$ to damage the cell walls. The treated cells were collected and washed with solution containing $20 \mathrm{~g} / \mathrm{L}$ of sea salt for once and then with solution containing $50 \mathrm{mM}$ sucrose for three times. Ten microliters of DNA ( $>500 \mathrm{ng} / \mu \mathrm{L}$ ) were used to transform $100 \mu \mathrm{L}$ of treated cells by electroporation. The condition for electroporation was $2000 \mathrm{~V}$ field strength, $50 \mu \mathrm{F}$ capacitance, $200 \Omega$ resistance, and $2 \mathrm{~mm}$ cup. After electroporation, cells were recovered in $0.6 \mathrm{~mL}$ of the rich medium, and cultivated for $12 \mathrm{~h}$ at $25^{\circ} \mathrm{C}$ and $180 \mathrm{rpm}$. Then, $200 \mu \mathrm{L}$ of cell suspension were spread into basal medium plates containing antibiotics at suitable concentration. The concentrations of G418 and bleomycin were $100 \mu \mathrm{g} / \mathrm{mL}$ and $50 \mu \mathrm{g} / \mathrm{mL}$, respectively. The plates were cultivated at $25{ }^{\circ} \mathrm{C}$ for 5 days, and transformants were transferred into the basal medium plates containing $600 \mu \mathrm{g} / \mathrm{mL}$ of G418 or $200 \mu \mathrm{g} / \mathrm{mL}$ of bleomycin. The transformants that were able to grow on plates containing high resistant concentration were picked and further confirmed by PCR and RT-PCR.

\section{Analyses of cell density, lipid content, fatty acid profile, and NADPH content}

Cell density was determined by a UV-1750 spectrophotometer (Shimadzu, Japan) at $\mathrm{OD}_{660}$. For Nile Red analysis, $1.0 \mathrm{OD}\left(\mathrm{OD}_{660}\right)$ cells were harvested, washed, and re-suspended in $1 \mathrm{~mL}$ of phosphate buffer saline $(\mathrm{pH}$ 7.2). After adding $10 \mu \mathrm{L}$ Nile Red $(10 \mathrm{mM})$, cells were incubated at $37^{\circ} \mathrm{C}$ for $15 \mathrm{~min}$ and determined by a spectrophotometer (F-2700EL, HITACHI, Chiyoda, Japan). For total lipid content analysis, the method described previously was followed [29]. Briefly, total lipid of about $25.0 \mathrm{mg}$ of lyophilized Schizochytrium algae powder was 
extracted by solutions containing chloroform: methanol $(2: 1, v / v)$ with $0.01 \%$ butylated hydroxytoluene for three times. The extracts were then washed with $1.0 \mathrm{~mL}$ of solution containing $1.0 \mathrm{M} \mathrm{KCl}$ for once, and with double-distilled water. The solvents were removed using a vacuum concentrator system (ZLS-1, Hunan, China). Fatty acid profile analysis was conducted following the method described previously [29]. Briefly, approximately $25 \mathrm{mg}$ of lyophilized Schizochytrium algae powder was re-suspended in solutions containing $2 \mathrm{~mL}$ of methanol with $3 \%$ sulfuric acid and $2 \mathrm{~mL}$ of chloroform. The solutions were heated at $98{ }^{\circ} \mathrm{C}$ for $2 \mathrm{~h}$. After cooling, $1 \mathrm{~mL}$ of distilled water was added and vortexed for $20 \mathrm{~s}$. GC-MS experiments were performed using an Agilent 5975 MSD/7890 instrument (Agilent Corp, Santa Clara, CA, USA). The column was an HP-5MS (30 $\mathrm{m} \times 0.25 \mathrm{~mm} \times 0.25 \mu \mathrm{m}$ film; Restek, Bellefonte, PA, USA). Ultra high purity helium was used as the carrier gas in a constant flow mode of $1 \mathrm{~mL} / \mathrm{min}$, and $1 \mu \mathrm{L}$ of a given sample was injected in 1:2 split ratio mode. The temperature was kept at $80{ }^{\circ} \mathrm{C}$ for $2 \mathrm{~min}$, and increased to $250{ }^{\circ} \mathrm{C}$ at a rate of $10{ }^{\circ} \mathrm{C} / \mathrm{min}$. When it reached $250{ }^{\circ} \mathrm{C}$, the heating rate was decreased to $5{ }^{\circ} \mathrm{C} / \mathrm{min}$ until $300^{\circ} \mathrm{C}$. The temperature was hold at $300{ }^{\circ} \mathrm{C}$ for 10 min before the analysis was terminated. NIST 11 mass spectral library (NIST/EPA/NIH mass spectral library, 2011 edition) was used for identified fatty acid methyl esters. The NADPH content was measured using Coenzyme II $\operatorname{NADP}(\mathrm{H})$ content determination kit (Nanjing Jiancheng Bioengineering Institute, Nanjing, China). Briefly, 7.5 OD of cells were harvested at 48 or $72 \mathrm{~h}$, added with $1 \mathrm{~mL}$ of alkaline extract solution, and disrupted by cell disrupt apparatus. The solution was centrifuged at $14,000 \times g$ for $1 \mathrm{~h}$. Five hundred microliters of supernatant was extracted and added with $500 \mu \mathrm{L}$ of acid extract solution. The solution was centrifuged at $14,000 \times g$ for $10 \mathrm{~min}$, and the supernatant extracted for NADPH content determination. The reaction agents were prepared according to the manufacture's protocol. Distilled water was used as control. The absorbance wavelength was set at $570 \mathrm{~nm}$. The equation for calculating NADPH content was: NADPH content $(\mathrm{nmol} / \mathrm{OD})=0.0288 \times\left(\Delta A_{\text {(sample-control })}-0.072\right)$.

\section{RT-PCR and real-time PCR analyses}

Cell were harvested and re-suspended in Trizol reagent (Invitrogen, Camarillo, CA, USA). The extraction of total RNA was conducted using a miRNeasy Mini Kit (Qiagen, Valencia, CA, USA), and subsequent synthesis of cDNA was achieved using a SuperScript ${ }^{\circledR}$ III FirstStrand Synthesis SuperMix kit (Thermo-Fisher, Waltham, MA, USA). The cDNA was used as the template for RTPCR analysis with the primers listed in Additional file 2: Table S4. Real-time PCR reactions were performed using a StepOne Plus Real-Time PCR (Applied Biosystems, Foster City, CA, USA). The condition for real-time PCR was according to the protocol of UltraSYBR Mixture (CoWin Biotech. Co. Ltd., Beijing, China). 18S rRNA was used as an internal control. The relative transcription levels of FAS, $\operatorname{orf} \mathrm{A}, \operatorname{orf} \mathrm{B}$, and $\operatorname{orfC}$ genes were calculated using the $2^{-\Delta \Delta \mathrm{Ct}}$ method [57]. The primers used for real-time PCR analysis are listed in Additional file 2: Table S4.

\section{Determination of enzyme activity}

The 5.0 OD $\left(\mathrm{OD}_{660}\right)$ of cells was collected at 48 and $72 \mathrm{~h}$, and then washed using PBS buffer. The cell sediments were re-suspended in an extraction buffer (containing $100 \mathrm{mM} \mathrm{KH} \mathrm{PO}_{4} / \mathrm{KOH}(\mathrm{pH} 7.5), 20 \%$ (v/v) glycerol), and disrupted by HNX-2 cell disruptor (Honour, Tianjin, China). The cell homogenates were centrifuged at $14,000 \times g$ (Eppendorf 5430R, Hamburg, Germany) for $30 \mathrm{~min}$ at $4{ }^{\circ} \mathrm{C}$, and the supernatants were used for enzyme and protein content analysis. The protein concentration of the supernatants was determined by the Bradford protein assay using Coomassie Brilliant Blue G-250 (Solarbio, Beijing, China) according to the manufacturer's instructions. The activity of $\mathrm{NADP}^{+}$-dependent malic enzyme was measured following the methods described previously [17]. Briefly, cell extract was added into the reaction solution containing $0.5 \mathrm{mM}$ L-malate, $4 \mathrm{mM} \mathrm{MnCl}$, and $0.23 \mathrm{mM}$ TPN in $66.67 \mathrm{mM}$ triethanolamine buffer at $\mathrm{pH} 7.4$, and incubated at $25^{\circ} \mathrm{C}$ for $10 \mathrm{~min}$. The NADPH formed was determined at $340 \mathrm{~nm}$. The enzyme activity was defined as the conversion of $1.0 \mu \mathrm{M}$ of L-malate and NADP to pyruvate, $\mathrm{CO}_{2}$ and $\mathrm{NADPH}$ per minute at $\mathrm{pH} 7.4$ at $25^{\circ} \mathrm{C}$ [17]. The activity of acetyl-CoA carboxylase was determined as described previously [58, 59]. Briefly, cell extract solution was added into a solution containing $1 \mathrm{mM}$ acetyl-CoA, $15 \mathrm{mM} \mathrm{KHCO}_{3}, 5 \mathrm{mM} \mathrm{MnCl}$, and $5 \mathrm{mM}$ ATP, $1 \mathrm{mg} /$ $\mathrm{mL}$ bovine serum albumin, and $3 \mathrm{mg} / \mathrm{L}$ biotin in $100 \mathrm{mM}$ phosphate buffer at $\mathrm{pH}$ 8.0. The mixture was incubated at $30{ }^{\circ} \mathrm{C}$, and equal aliquots were extracted every $2 \mathrm{~min}$ and immediately added $10 \%(\mathrm{w} / \mathrm{v})$ trifluoroacetic acid to stop the reaction. The acetyl-CoA in each aliquot reacted with oxaloacetate to form citrate and CoA-SH. The CoA$\mathrm{SH}$ was determined by reacting with dithiobisnitrobenzoic acid to form a yellow compound, which was assessed spectrophotometrically at $412 \mathrm{~nm}$. The enzyme activity was defined as the consumed of $1.0 \mu \mathrm{M}$ of acetyl-CoA per min at $\mathrm{pH} 8.0$ at $30^{\circ} \mathrm{C}$. For determination of the feedback inhibition on acetyl-CoA carboxylase, C16-CoA was added into the cell-free extract of Schizochytrium sp. S31 at a final concentration of 50 or $100 \mu \mathrm{M}$. The activities of $\mathrm{NADP}^{+}$-dependent malic enzyme and acetyl-CoA 
carboxylase were normalized by the protein concentration of the supernatants.

\section{LC-MS metabolomic analysis}

The LC-MS metabolomic analysis was carried out based on the method described previously [60]. Briefly, approximately 5.0 $\mathrm{OD}\left(\mathrm{OD}_{660}\right)$ of cells were harvested at 48 and $72 \mathrm{~h}$ by centrifugation at $8000 \times g$ for $5 \mathrm{~min}$ at room temperature (Eppendorf 5430R, Hamburg, Germany). The cells were immediately frozen at $-80^{\circ} \mathrm{C}$ before use. The cells were added into a $900 \mu \mathrm{L}$ of solution containing $\mathrm{MeOH} / \mathrm{H}_{2} \mathrm{O}\left(\mathrm{v} / \mathrm{v}, 8: 2,-80^{\circ} \mathrm{C}\right)$, quickly frozen in liquid nitrogen, and then thawed in room temperature. The samples were then frozen-thawed for three times. The supernatant was harvested by centrifugation at $15,000 \times g$ for $5 \mathrm{~min}$ at $-4{ }^{\circ} \mathrm{C}$. The sediments were re-suspended in $500 \mu \mathrm{L}$ of $80: 20 \mathrm{MeOH} / \mathrm{H}_{2} \mathrm{O}\left(-80^{\circ} \mathrm{C}\right)$ and then repeated the above extraction process. The supernatant of the second extraction was mixed with the first, and the solvents were removed using a vacuum concentrator system (ZLS-1, Hunan, China). The sediment was resolved in $100 \mu \mathrm{L}$ of distilled water. LC-MS analysis was performed on an Agilent 1260 series binary HPLC system (Agilent Technologies, Waldbronn, Germany) using a SYnergi Hydro-RP (C18) $150 \mathrm{~mm} \times 2.0 \mathrm{~mm}$ I.D., $4 \mu \mathrm{m} 80$ $\AA$ A particles column (Phenomenex, Torrance, CA, USA), coupled to an Agilent 6410 triple quadrupole mass analyser equipped with an electrospray ionization source. An aqueous solution containing $10 \mathrm{mM}$ tributylamine and a $100 \%$ methanol (HPLC grade) solution were used as mobile phase $A$ and $B$, respectively. The flow rate was set at $0.2 \mathrm{~mL} / \mathrm{min}$. The MS was operated in negative mode for multiple reaction monitoring development, method optimization, and sample analysis. Sample injected volume was $10 \mu \mathrm{L}$; capillary voltage was $4000 \mathrm{~V}$; nebulizer gas flow rate was $10 \mathrm{~L} / \mathrm{min}$; nebulizer gas pressure was $50 \mathrm{psi}$; nitrogen nebulizer gas temperature was $300{ }^{\circ} \mathrm{C}$. Data were obtained using Agilent Mass Hunter workstation LC/QQQ acquisition software (version B.04.01) and chromatographic peaks were subsequently integrated via Agilent Qualitative Analysis software (version B.04.00). Metabolomic data were normalized by interior control and cell number, and then subjected to the principal component analysis performed by SIMCA-P 11.5 software. Heatmaps of metabolomic data were created using the MultiExperiment Viewer software. For measuring the intracellular propionyl-CoA concentration, approximately $5.0 \mathrm{OD}\left(\mathrm{OD}_{660}\right)$ of cells were harvested at 48 and $72 \mathrm{~h}$, and the exaction and analysis methods followed the LC-MS metabolomic analysis described above. The standard propionyl-CoA purchased from Sigma (St. Louis, MO, USA) was used for determination of the standard curve of propionyl-CoA. The intracellular
propionyl-CoA concentration was normalized by the value of $\mathrm{OD}_{660}$, which can be used for representing the biomass concentration in Schizochytrium [29].

\section{Statistical analysis}

All experiments were conducted with at least three biological replicates. Statistical analyses were performed using two-tailed Student's $t$ tests, and $p<0.05$ was considered indicative of statistical significance.

\section{Additional files}

Additional file 1: Fig. S1. Comparison of acetyl-CoA carboxylase activity after adding C16-CoA into cell-free extract of Schizochytrium sp. S31. 0 represents adding $0 \mu \mathrm{M}$ of $\mathrm{C} 16-\mathrm{COA} ; 50$ represents adding $50 \mu \mathrm{M}$ of $\mathrm{C} 16$ CoA; 100 represents adding $100 \mu \mathrm{M}$ of $\mathrm{C} 16-\mathrm{CoA} .{ }^{*}$ indicated $p<0.05 .{ }^{* *}$ indicated $p<0.01$. Fig. S2. Expression of a codon-optimized $E L O 3$ gene from Mortierella alpina in Schizochytrium. A) Schematic map of the ELO3 gene expression cassette, with the indicated primers. 1: 18s upstream; 2: CaMV 35s promoter; 3: ELO3 gene; 4: Nos terminator; 5: a tubulin promoter from Schizochytrium; 6: bleomycin resistance gene; 7: CYC1 terminator; 8: 18s downstream; B) Genomic PCR detection with primer 1 and primer 2. M: $1 \mathrm{~kb}$ marker from Vazyme company; 1: S-E strain; 2: wild type. C) RT-PCR detection with primer 3 and primer 4. M: 1 kb marker from Thermo Scientific company; 1: S-E strain; 2: wild type. Fig. S3. Expression of a malic enzyme gene from C. cohnii in Schizochytrium. A) Schematic map of the malic enzyme expression cassette, with the indicated primers. 1: 18 s upstream; 2: CaMV 35s promoter; 3: neomycin resistance gene; 4: CaMV poly(A) terminator; 5: malic enzyme gene; 6: 18s downstream; B) Genomic PCR detection with primer 5 and primer 6. M: $1 \mathrm{~kb}$ marker; 1: water; 2: wild type; 3: S-M strain; C) RT-PCR detection with primer 7 and primer 8. 1: water; 2: wild type; 3 S-M strain. Fig. S4. Malic enzyme activity and NADPH content in the wild type and S-M strains. A) The malic enzyme activity. Blue: wild type; Purple: S-M strain. ${ }^{*}$ indicated $p<0.05$; B) NADPH content. Blue: wild type; Purple: S-M strain. ${ }^{*}$ indicated $p<0.05$, $*^{*}$ indicated $p<0.01$. Fig. S5. Expression of a codon-optimized ELO3 gene from M. alpina in S-M strain. A) Schematic map of the ELO3 gene expression cassette, with the indicated primers. 1: CaMV 35s promoter; 2: ELO3 gene; 3: Nos terminator; 4: a tubulin promoter from Schizochytrium; 5 : bleomycin resistance gene 6: CYC1 terminator; B) Genomic PCR detection with primer 1 and primer 2. M: 1 kb marker; 1: S-M-E strain; 2: S-M strain; C) RT-PCR detection with primer 3 and primer 4. M: 1 kb marker; 1: S-M strain; 2: S-M-E strain. Fig. S6. MS spectrums of methyl fatty acids detected among strains. Fig. S7. Principal component analysis of LC-MS targeted metabolomics of S-M and S-M-E strains. A) 48 h; B) 72 h. Purple: S-M strain; Green: S-M-E strain.

Additional file 2: Table S1. Fatty acids profiles in the wild type, S-E, S-M and S-M-E strains. Table S2. LC-MS metabolomics data sets of S-M and S-M-E strains. Table S3. The production cost of DHA and OCFAs in the wild type and S-M-E strains. Table S4. Primers used in this study.

Additional file 3: File S1. The sequence of codon-optimized ELO3 gene from Mortierella alpina.

\section{Abbreviations}

ACC: acetyl-CoA carboxylase; Ac-CoA: acetyl-CoA; ADP: adenosine diphosphate; AKG: 2-oxoglutaric acid; ALA: alanine; AMP: adenosine monophosphate; ATP: adenosine triphosphate; ASP: aspartic acid; C14: C14:0; C16: C16:0; C18: C18:0 and C18:1; CIT: citrate; Citric: citric acid; DHA: docosahexaenoic acid; FAS: fatty acid synthase; F6P: fructose 6-phosphate; FBP: fructose 1,6-bisphosphate; FUM: fumaric acid; G6P: glucose-6-phosphate; GAP: glyceraldehyde 3-phosphate; GLU: glutamic acid; LEU: isoleucine; LYS: Iysine; MAL: malate; ME: malic enzyme; NADPH: nicotinamide adenine dinucleotide phosphate; $\mathrm{NADP}+$ : oxidized form of nicotinamide adenine dinucleotide phosphate; 
NAD+: nicotinamide adenine dinucleotide; OCFAs: odd-chain fatty acids; OXA: oxaloacetic acid; 3-PG: 3-phosphoglyceric acid; 6PG: 6-phosphogluconate; PEP: phosphoenolpyruvic acid; PHE: phenylalanine; PKS: polyketide synthase; PYR: pyruvate; Ri5P: ribose 5-phosphate; SER: serine; SUM: succinic acid; X5P: xylulose 5-phosphate; VAL: valine.

\section{Acknowledgements}

We sincerely thank Dr. Tao Sun from Tianjin University for the discussion.

\section{Authors' contributions}

FZW performed the major experiments and wrote the draft manuscript; $Y B$, $J J D, M M L$, and JYC helped with some of the experiments; FZW, LC, and WZ analyzed the data; FZW, YB, LC, and WZ designed and revised the manuscript. All authors read and approved the final manuscript.

\section{Funding}

This research was supported by Grants from the National Natural Science Foundation of China (Nos. 31770100, 21621004, 31370115, and 91751102), the Doctoral Program of Higher Education of China (Nos. 20120032110020 and 20130032120022), the Tianjin Municipal Science Foundation (Nos. 18JCQNJC10000), and Zaoneng Biotechnology Inc.

\section{Availability of data and materials}

All data generated or analyzed during this study are included in this published article and its additional files.

\section{Ethics approval and consent to participate}

Not applicable.

\section{Consent for publication}

All authors agree to publication.

\section{Competing interests}

The authors declare that they have no competing interests.

\section{Author details}

${ }^{1}$ Center for Biosafety Research and Strategy, Tianjin University, Tianjin, People's Republic of China. ${ }^{2}$ Laboratory of Synthetic Microbiology, School of Chemical Engineering \& Technology, Tianjin University, Tianjin 300072, People's Republic of China. ${ }^{3}$ Frontier Science Center for Synthetic Biology and Key Laboratory of Systems Bioengineering (MOE), School of Chemical Engineering and Technology, Tianjin University, Tianjin 300350, People's Republic of China. ${ }^{4}$ SynBio Research Platform, Collaborative Innovation Center of Chemical Science and Engineering, Tianjin University, Tianjin 300350, People's Republic of China.

Received: 3 January 2019 Accepted: 3 June 2019

Published online: 08 June 2019

\section{References}

1. Calder PC. Functional roles of fatty acids and their effects on human health. Jpen-Parenter Enter. 2015;39:18s-32s.

2. Forouhi NG, Koulman A, Sharp SJ, Imamura F, Kroger J, Schulze MB, et al. Differences in the prospective association between individual plasma phospholipid saturated fatty acids and incident type 2 diabetes: the EPICInterAct case-cohort study. Lancet Diabetes Endo. 2014;2(10):810-8.

3. Holman RT, Johnson SB, Kokmen E. Deficiencies of polyunsaturated fatty acids and replacement by nonessential fatty acids in plasma lipids in multiple sclerosis. Proc Natl Acad Sci USA. 1989;86(12):4720-4.

4. Jenkins B, West JA, Koulman A. A review of odd-chain fatty acid metabolism and the role of pentadecanoic acid (C15:0) and heptadecanoic acid (C17:0) in health and disease. Molecules. 2015;20(2):2425-44.

5. Khaw KT, Friesen MD, Riboli E, Luben R, Wareham N. Plasma phospholipid fatty acid concentration and incident coronary heart disease in men and women: the EPIC-Norfolk Prospective Study. Plos Med. 2012;9(7):e1001255.

6. Bauer K, Garbe D, Surburg H. Common ragrance and flavor materials: preparation, properties and uses. 4th ed. New York: Wiley; 2008.
7. Braude GL. Preparation of polymeric plasticizers from tall oil fatty acids. US Patent 3337594. 1967.

8. Telos SRL, Bader S, Masiello S. Cosmetic composition containing azelaic acid. wo patent 9917714. 1999.

9. Wu H, San KY. Efficient odd straight medium chain free fatty acid production by metabolically engineered Escherichia coli. Biotechnol Bioeng. 2014;111(11):2209-19.

10. Knothe $\mathrm{G}$. Dependence of biodiesel fuel properties on the structure of fatty acid alkyl esters. Fuel Process Technol. 2005;86(10):1059-70.

11. Knothe G. "Designer" biodiesel: optimizing fatty ester (composition to improve fuel properties. Energy Fuel. 2008;22(2):1358-64.

12. Park YK, Dulermo T, Ledesma-Amaro R, Nicaud JM. Optimization of odd chain fatty acid production by Yarrowia lipolytica. Biotechnol Biofuels. 2018;11:158

13. Vlaeminck B, Fievez V, Cabrita ARJ, Fonseca AJM, Dewhurst RJ. Factors affecting odd- and branched-chain fatty acids in milk: a review. Anim Feed Sci Tech. 2006;131(3-4):389-417.

14. Guo DS, Ji XJ, Ren LJ, Li GL, Sun XM, Chen KQ, et al. Development of a scale-up strategy for fermentative production of docosahexaenoic acid by Schizochytrium sp. Chem Eng Sci. 2018;176:600-8.

15. Mendes A, Reis A, Vasconcelos R, Guerra P, da Silva TL. Crypthecodinium cohnii with emphasis on DHA production: a review. J Appl Phycol. 2009;21(2):199-214

16. Chang GF, Gao NS, Tian GW, Wu QH, Chang M, Wang XG. Improvement of docosahexaenoic acid production on glycerol by Schizochytrium sp. S31 with constantly high oxygen transfer coefficient. Bioresour Technol. 2013;142:400-6.

17. Diao JJ, Song XY, Cui JY, Liu LS, Shi ML, Wang FZ, et al. Rewiring metabolic network by chemical modulator based laboratory evolution doubles lipid biosynthesis in Crypthecodinium cohnii. Metab Eng. 2018;51:88-98.

18. Lippmeier JC, Crawford KS, Owen CB, Rivas AA, Metz JG, Apt KE. Characterization of both polyunsaturated fatty acid biosynthetic pathways in Schizochytrium sp. Lipids. 2009;44(7):621-30.

19. Yan JF, Cheng RB, Lin XZ, You S, Li K, Rong H, et al. Overexpression of acetyl-CoA synthetase increased the biomass and fatty acid proportion in microalga Schizochytrium. Appl Microbiol Biotechnol. 2013;97(5):1933-9.

20. Zhang S, He Y, Sen B, Chen X, Xie Y, Keasling JD, et al. Alleviation of reactive oxygen species enhances PUFA accumulation in Schizochytrium sp. through regulating genes involved in lipid metabolism. Metab Eng Commun. 2018;6:39-48

21. Li ZP, Meng T, Ling XP, Li J, Zheng CQ, Shi YY, et al. Overexpression of malonyl-CoA: ACP transacylase in Schizochytrium sp. to improve polyunsaturated fatty acid production. J Agric Food Chem. 2018;66(21):5382-91.

22. Ren $L J$, Zhuang $X Y$, Chen SL, Ji XJ, Huang $H$. Introduction of omega-3 desaturase obviously changed the fatty acid profile and sterol content of Schizochytrium sp. J Agric Food Chem. 2015;63(44):9770-6.

23. Cao YX, Xiao WH, Liu D, Zhang JL, Ding MZ, Yuan YJ. Biosynthesis of oddchain fatty alcohols in Escherichia coli. Metab Eng. 2015;29:113-23.

24. Clementina D, Clomburg JM, Miller EN, Gonzalez R. Engineered reversal of the $\beta$-oxidation cycle for the synthesis of fuels and chemicals. Nature. 2011:476:355-9.

25. Tseng HC, Prather KLJ. Controlled biosynthesis of odd-chain fuels and chemicals via engineered modular metabolic pathways. Proc Natl Acad Sci USA. 2012;109(44):17925-30.

26. Lan JCW. The optimization of docosahexaenoic acid production from waste by Schizochytrium limacinum SR21. J Biotechnol. 2015;208:S33.

27. Jiang Y, Fan KW, Wong RDY, Chen F. Fatty acid composition and squalene content of the marine microalga Schizochytrium mangrovei. J Agric Food Chem. 2004;52(5):1196-200.

28. Zhu LY, Zhang XC, Ji L, Song XJ, Kuang CH. Changes of lipid content and fatty acid composition of Schizochytrium limacinum in response to different temperatures and salinities. Process Biochem. 2007;42(2):210-4.

29. Wang K, Sun T, Cui JY, Liu LS, Bi YQ, Pei GS, et al. Screening of chemical modulators for lipid accumulation in Schizochytrium sp. S31. Bioresour Technol. 2018;260:124-9.

30. Andre C, Haslam RP, Shanklin J. Feedback regulation of plastidic acetylCoA carboxylase by 18:1-acyl carrier protein in Brassica napus. Proc Natl Acad Sci USA. 2012;109(25):10107-12.

31. Shintani DK, Ohlrogge JB. Feedback inhibition of fatty-acid synthesis in tobacco suspension cells. Plant J. 1995;7:577-87. 
32. Roessler PG. Purification and characterization of acetyl-CoA carboxylase from the diatom Cyclotella cryptica. Plant Physiol. 1990;92(1):73-8.

33. Sakuradani E, Nojiri M, Suzuki H, Shimizu S. Identification of a novel fatty acid elongase with a wide substrate specificity from arachidonic acid-producing fungus Mortierella alpina 1S-4. Appl Microbiol Biotechnol. 2009;84(4):709-16.

34. Daniel JM, Xue ZX, Zhu QQ. Mortierella alpina C16/18 fatty acid elongase. US Patent 7470532B2. 2008.

35. Xue Z, Sharpe PL, Hong SP, Yadav NS, Xie D, Short DR, et al. Production of omega-3 eicosapentaenoic acid by metabolic engineering of Yarrowia lipolytica. Nat Biotechnol. 2013;31(8):734-40.

36. Ren $L$, Huang $H$, Xiao AH, Lian M, Jin LJ, Ji XJ. Enhanced docosahexaenoic acid production by reinforcing acetyl-coA and NADPH supply in Schizochytrium sp. HX-308. Bioprocess Biosyst Eng. 2009;32:837-43.

37. Liu B, Liu J, Sun PP, Ma XN, Jiang Y, Chen F. Sesamol enhances cell growth and the biosynthesis and accumulation of docosahexaenoic acid in the microalga Crypthecodinium cohnii. J Agric Food Chem. 2015;63(23):5640-5.

38. Li JH, Niu XF, Pei GS, Sui X, Zhang XQ, Chen L, et al. Identification and metabolomic analysis of chemical modulators for lipid accumulation in Crypthecodinium cohnii. Bioresour Technol. 2015;191:362-8.

39. Silverman AM, Qiao KJ, Xu P, Stephanopoulos G. Functional overexpression and characterization of lipogenesis-related genes in the oleaginous yeast Yarrowia lipolytica. Appl Microbiol Biotechnol. 2016;100(8):3781-98.

40. Xu P, Qiao KJ, Stephanopoulos G. Engineering oxidative stress defense pathways to build a robust lipid production platform in Yarrowia lipolytica. Biotechnol Bioeng. 2017;114(7):1521-30

41. Liu H, Marsafari M, Deng L, Xu P. Understanding lipogenesis by dynamically profiling transcriptional activity of lipogenic promoters in Yarrowia lipolytica. Appl Microbiol Biotechnol. 2019;103(7):3167-79.

42. Li YJ, Fei XW, Deng XD. Novel molecular insights into nitrogen starvationinduced triacylglycerols accumulation revealed by differential gene expression analysis in green algae Micractinium pusillum. Biomass Bioenerg. 2012;42:199-211.

43. Li YQ, Xu H, Han FX, Mu JX, Chen D, Feng B, et al. Regulation of lipid metabolism in the green microalga Chlorella protothecoides by heterotrophy-photoinduction cultivation regime. Bioresour Technol. 2015:192:781-91.

44. Gamez-Meza N, Noriega-Rodriguez JA, Medina-Juarez LA, Ortega-Garcia J, Monroy-Rivera J, Toro-Vazquez FJ, et al. Concentration of eicosapentaenoic acid and docosahexaenoic acid from fish oil by hydrolysis and urea complexation. Food Res Int. 2003:36(7):721-7.

45. Guo DS, Ji XJ, Ren LJ, Li GL, Huang H. Improving docosahexaenoic acid production by Schizochytrium sp. using a newly designed high-oxygensupply bioreactor. Aiche J. 2017;63(10):4278-86.

46. Tan KWM, Lee YK. The dilemma for lipid productivity in green microalgae: importance of substrate provision in improving oil yield without sacrificing growth. Biotechnol Biofuel. 2016;9:255.

47. Los M, Czyz A, Sell E, Wegrzyn A, Neubauer P, Wegrzyn G. Bacteriophage contamination: is there a simple method to reduce its deleterious effects in laboratory cultures and biotechnological factories? J Appl Genet. 2004;45(1):111-20.
48. Hauvermale A, Kuner J, Rosenzweig B, Guerra D, Diltz S, Metz JG. Fatty acid production in Schizochytrium sp.: involvement of a polyunsaturated fatty acid synthase and a type I fatty acid synthase. Lipids. 2006;41(8):739-47.

49. Metz JG, Roessler P, Facciotti D, Levering C, Dittrich F, Lassner M, et al. Production of polyunsaturated fatty acids by polyketide synthases in both prokaryotes and eukaryotes. Science. 2001;293(5528):290-3.

50. Ratledge $C$. The role of malic enzyme as the provider of NADPH in oleaginous microorganisms: a reappraisal and unsolved problems. Biotechnol Lett. 2014;36(8):1557-68.

51. Sauer U, Canonaco F, Heri S, Perrenoud A, Fischer E. The soluble and membrane-bound transhydrogenases UdhA and PntAB have divergent functions in NADPH metabolism of Escherichia coli. J Biol Chem. 2004;279(8):6613-9

52. Song $X J$, Tan YZ, Liu YJ, Zhang JT, Liu GL, Feng YG, et al. Different impacts of short-chain fatty acids on saturated and polyunsaturated fatty acid biosynthesis in Aurantiochytrium sp. SD116. J Agric Food Chem. 2013:61(41):9876-81.

53. Cui GZ, Ma ZX, Liu YJ, Feng YG, Sun ZJ, Cheng YR, et al. Overexpression of glucose-6-phosphate dehydrogenase enhanced the polyunsaturated fatty acid composition of Aurantiochytrium sp. SD116. Algal Res. 2016;19:138-45.

54. Rosenberg JN, Oyler GA, Wilkinson L, Betenbaugh MJ. A green light for engineered algae: redirecting metabolism to fuel a biotechnology revolution. Curr Opin Biotechnol. 2008;19(5):430-6.

55. Tan KW, Lee YK. Expression of the heterologous Dunaliella tertiolecta fatty acyl-ACP thioesterase leads to increased lipid production in Chlamydomonas reinhardtii. J Biotechnol. 2017;247:60-7.

56. Adachi T, Sahara T, Okuyama H, Morita N. Glass bead-based genetic transformation: an efficient method for transformation of Thraustochytrid microorganisms. J Oleo Sci. 2017:66(7):791-5.

57. Livak KJ, Schmittgen TD. Analysis of relative gene expression data using real-time quantitative PCR and the $2(\mathrm{~T})(-$ Delta Delta $\mathrm{C})$ method. Methods. 2001;25(4):402-8

58. Liu J, Pei GS, Diao JJ, Chen ZX, Liu LS, Chen L, et al. Screening and transcriptomic analysis of Crypthecodinium cohnii mutants with high growth and lipid content using the acetyl-CoA carboxylase inhibitor sethoxydim. Appl Microbiol Biotechnol. 2017;101(15):6179-91.

59. Willis LB, Omar WSW, Sambanthamurthi R, Sinskey AJ. Non-radioactive assay for acetyl-CoA carboxylase activity. J Oil Palm Res. 2008;2:30-6.

60. Sui X, Niu XF, Shi ML, Pei GS, Li JH, Chen L, et al. Metabolomic analysis reveals mechanism of antioxidant butylated hydroxyanisole on lipid accumulation in Crypthecodinium cohnii. J Agric Food Chem. 2014;62(51):12477-84.

\section{Publisher's Note}

Springer Nature remains neutral with regard to jurisdictional claims in published maps and institutional affiliations.

Ready to submit your research? Choose BMC and benefit from

- fast, convenient online submission

- thorough peer review by experienced researchers in your field

- rapid publication on acceptance

- support for research data, including large and complex data types

- gold Open Access which fosters wider collaboration and increased citations

- maximum visibility for your research: over 100M website views per year

At BMC, research is always in progress.

Learn more biomedcentral.com/submissions 